\title{
Partial, selective survival of nitrergic neurons in chagasic megacolon
}

\author{
Samir Jabari • Alexandre B. M. da Silveira • \\ Enio C. de Oliveira - Salustiano G. Neto • \\ Karl Quint · Winfried Neuhuber · Axel Brehmer
}

Accepted: 9 December 2010/Published online: 24 December 2010

(C) The Author(s) 2010. This article is published with open access at Springerlink.com

\begin{abstract}
One frequent chronic syndrome of Chagas' disease is megacolon, an irreversible dilation of a colonic segment. Extensive enteric neuron loss in the affected segment is regarded as key factor for deficient motility. Here, we assessed the quantitative balance between cholinergic and nitrergic neurons representing the main limbs of excitatory and inhibitory colonic motor innervation, respectively. From surgically removed megacolonic segments of four patients, each three myenteric wholemounts (from non-dilated oral, megacolonic and non-dilated anal parts) was immunohistochemically triple-stained for choline acetyltransferase, neuronal nitric oxide synthase (NOS) and the panneuronal human neuronal protein $\mathrm{Hu}$ C/D. Degenerative changes were most pronounced in the megacolonic and anal regions, e.g. bulked, honeycomb-like ganglia with few neurons which were partly enlarged or atrophic or vacuolated. Neuron counts from each 15 ganglia of 12 megacolonic wholemounts were compared with those of 12 age- and region-matched controls. Extensive neuron loss, mainly in megacolonic and anal wholemounts,
\end{abstract}

S. Jabari · W. Neuhuber $\cdot$ A. Brehmer $(\square)$

Institute of Anatomy I, University of Erlangen-Nuremberg,

Krankenhausstr. 9, 91054 Erlangen, Germany

e-mail: axel.brehmer@anatomie1.med.uni-erlangen.de

A. B. M. da Silveira

Human Anatomy Sector, ICBIM, Universidade Federal de

Uberlândia, Uberlândia, Minas Gerais 38.400-902, Brazil

E. C. de Oliveira $\cdot$ S. G. Neto

Department of Surgery, Medical School,

Universidade Federal de Goiás, Goiânia, GO 74.605-020, Brazil

K. Quint

Institute for Surgical Research, University of Marburg,

Baldingerstr, 35043 Marburg, Germany was obvious. In all three regions derived from megacolonic samples, the proportion of NOS-positive neurons (control: $55 \%)$ was significantly increased: in non-dilated oral parts to $61 \%(p=0.003)$, in megacolonic regions to $72 \%$ $(p<0.001)$ and in non-dilated anal regions to $78 \%$ $(p<0.001)$. We suggest the chronic dilation of megacolonic specimens to be due to the preponderance of the nitrergic, inhibitory input to the intestinal muscle. However, the observed neuronal imbalance was not restricted to the dilated regions: the non-dilated anal parts may be innervated by ascending, cholinergic axons emerging from less affected, more anally located regions.

Keywords Acquired hypoganglionosis - Enteric nervous system $\cdot$ Myenteric plexus $\cdot$ Neurodegeneration

\section{Introduction}

Megacolon, chronic dilation of a colonic segment, is a structural sign associated with various gastrointestinal disorders. Its functional and clinical consequences are primarily based upon severely disturbed gut motility ("aperistalsis"; Köberle 1968) and often require surgical intervention (Di Nardo et al. 2008; Thapar 2009). Originally, in the context of Hirschsprung's disease, the term megacolon has been used misleadingly (Howard 1972). This disease is based on a developmental deficiency resulting in an aganglionosis, i.e. the absence of enteric neurons, frequently in the rectosigmoidal region of the large intestine (Heanue and Pachnis 2007). The functional consequence of aganglionosis is permanent contraction of the gut musculature mainly due to the lack of inhibitory innervation. Subsequently, the segment oral to this obstruction dilates because of stasis of ingesta. Thus, the 
megacolonic segment in Hirschsprung's disease, based on a congenital aganglionosis anal from the dilation, is not primarily but secondarily affected (Köberle 1968; Howard 1972).

Another, acquired reason for the development of megacolon can occur after infection with the parasite Trypanosoma cruzi resulting in Chagas' disease. This was originally endemic in Latin American regions; however, globalization enables the parasite to migrate to other continents (Coura and Vinas 2010). By far, the most frequent chronic syndromes of Chagas' disease which commonly develop mainly in hollow muscle organs are cardiopathies, followed by two enteromegalies, i.e. megacolon and megaesophagus (Köberle 1968; Teixeira et al. 2006; Coura and Vinas 2010). Also in the pathogenesis of chagasic megacolon, extensive neuronal absence plays a major role. In contrast to the secondary megacolon in Hirschsprung's disease, the chagasic megacolon is not the consequence of an anally located obstruction. Dramatic reduction of enteric neuron number occurs in the segment itself which subsequently transforms into a primary megacolon (Köberle 1968; Fernandez et al. 1992; Meneghelli 2004; Iantorno et al. 2007). Thus, the chagasic megacolon is based on an acquired hypoganglionosis in the affected segment itself.

Köberle (1968) suggested that neuron loss in the chronic phase of Chagas' disease is a continuous process lasting decades and that functional disturbances, i.e. discomfort of patients related to impaired gut motility, precede manifest macroscopic alterations, e.g. megacolon. The 'natural experiment' of Hirschsprung's disease demonstrates that gut muscle in the absence of enteric neurons contracts tonically. Since irreversible, atonic dilation is the leading macroscopic feature of chagasic megacolon, it might be expected that the first and/or main cause is loss of excitatory neurons. Generally, these are represented by cholinergic neurons whereas nitrergic nerves represent an important part of the inhibitory limb of motor innervation (Grider 1989). Surprisingly, a reduction of nitrergic neurons has been noted on sections through chagasic megacolonic samples (Ribeiro et al. 1998; da Silveira et al. 2007). Thus, the question whether the dramatic loss of enteric neurons afflicts the different neuron types, e.g. excitatory and inhibitory, proportionally or spares specific populations, is not consistently answered.

In the present study, we evaluated the balance between these two general neuronal limbs of enteric circuits by triplelabel immunohistochemistry in wholemount preparations of the myenteric plexus. Nitrergic neurons were detected using an antibody against neuronal nitric oxide synthase (NOS), for cholinergic neurons we applied an antibody against the common choline acetyltransferase (ChAT) and the whole neuron population was demonstrated by an antibody against the human neuronal protein Hu C/D (HU; Phillips et al. 2004; Ganns et al. 2006; Beck et al. 2009). Previous studies have shown that most myenteric neurons contain either ChAT or NOS and that the quantitative relation between both populations is largely balanced (Murphy et al. 2007; Beck et al. 2009). We included not only the megacolonic zones itself, but also the non-dilated oral and anal parts of the resected specimens. These samples of a Brazil, megacolonic patients group were compared with those of a Brazil, non-megacolonic, nonchagasic control group. Furthermore, to answer the question if there exists a different balance level of cholinergic and nitrergic neurons between different ethnic groups, a German, non-chagasic control group was also included.

\section{Materials and methods}

Tissue handling

The use of human tissues for these experiments was approved by the Ethics Committee of the University of Erlangen-Nuremberg (Germany) as well as the Human Ethics Committee of the Federal Universities of Minas Gerais (Brazil). Tissues were used with the patients' written consent. Three groups of tissue samples all derived from the left (descending or sigmoid) colon were collected, a German control group (6 patients: median age 65.5 years, 4 female, 2 male), a Brazilian control group (6 patients: median age 65 years, 4 female, 2 male) and the megacolonic (Brazilian) group ( 4 patients: median age 69 years, 2 female, 2 male).

Clinical complaints of megacolonic patients were longlasting constipation (up to several years), abdominal pain and distension. Clinical diagnosis of megacolon was assured by barium enema examination. Serological tests for Chagas disease (indirect immunofluorescence, hemagglutination and enzyme-linked immunosorbent assay, ELISA) revealed three of the megacolonic patients to be seropositive, whereas one megacolonic patient (69 years, male) was seronegative for Chagas disease.

Specimens of the two control groups were derived from the patients suffering from tumours. Only tissues obtained from the marginal parts of the resected gut segments (supposed to be not influenced by the disease) were included. The specimens of the megacolonic patients included the megacolonic, dilated portion and about 3-4 cm non-dilated gut oral and anal to the dilated segment, respectively (Fig. 1). From these three parts, each one piece $(3 \times 3 \mathrm{~cm}$ from oral and anal, about $10 \times 10 \mathrm{~cm}$ from the dilated part) was excised and treated as described below. Intestinal segments were transported in physiological saline ( $\mathrm{pH} 7.3$ ) on ice to the laboratories. Upon arrival (1-6 h after resection) and without any further preincubation, the samples were pinned out 


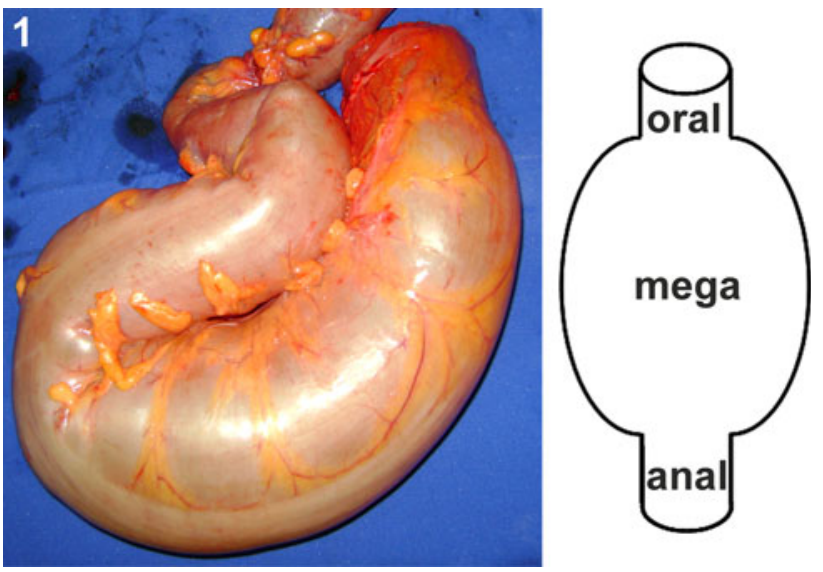

Fig. 1 Resected megacolonic segment from the male patient aged 69 years (seronegative). Oral, megacolonic and anal zones from which wholemounts were taken are schematically marked (right)

on a Sylgard-lined Petri dish and transferred to $4 \%$ formalin in $0.1 \mathrm{M}$ phosphate buffer ( $\mathrm{pH}$ 7.4) at room temperature for 2-4 h. After several washes in $0.05 \mathrm{M}$ Tris-buffered saline (TBS; pH 7.4), material was stored in TBS with added $0.05 \%$ thimerosal and Brazilian samples were sent by air mail to the German laboratory. Longitudinal muscle/myenteric plexus wholemounts ( $2 \mathrm{~cm}$ length, $1 \mathrm{~cm}$ width) from all segments were prepared, i.e. one per control patient, three per megacolonic patient: oral, megacolonic, anal (Fig. 1). Partly, it turned out necessary to prepare a second or even a third wholemount from megacolonic and anal segments (quantitative database, see below). Especially, wholemounts from these two segments were difficult to prepare due to thickness of musculature and amount of connective tissue.

\section{Immunohistochemistry}

The wholemounts were preincubated for $2 \mathrm{~h}$ in $0.05 \mathrm{M}$ TBS (pH 7.4) containing $1 \%$ bovine serum albumin (BSA), $0.5 \%$ Triton $\mathrm{X}-100,0.05 \%$ thimerosal and $5 \%$ normal donkey serum. After a rinse in TBS for $10 \mathrm{~min}$, they were incubated in a solution containing BSA, Triton X-100, thimerosal and the three primary antibodies (Table 1) for $72 \mathrm{~h}\left(4^{\circ} \mathrm{C}\right)$. After an overnight rinse in TBS at $4^{\circ} \mathrm{C}$, the three secondary antibodies (Table 1) were added in the same solution as the primary antibodies $(4 \mathrm{~h}$; room temperature) followed by a rinse in TBS (overnight; $4^{\circ} \mathrm{C}$ ).

To reduce lipofuscin autofluorescence, specimens were incubated in ammonium acetate buffer ( $\mathrm{pH}$ 5.0) containing $1 \mathrm{mM} \mathrm{CuSO}_{4}$ for $2 \mathrm{~h}$ followed by a short rinse in distilled $\mathrm{H}_{2} \mathrm{O}$ (Schnell et al. 1999; Brehmer et al. 2004). Wholemounts were mounted in TBS-glycerol $(1: 1 ; \mathrm{pH} 8.6)$.

Negative controls for all three primary antibodies have been performed in earlier studies (Ganns et al. 2006; Beck et al. 2009). Here, we tested the specificity of the primary antibodies only in small $(1 \times 1 \mathrm{~cm})$, additionally prepared wholemounts from the four megacolonic portions by omitting the primary antibodies from the procedure described above. These preparations yielded no staining.

Image acquisition and quantitative evaluations

Specimens were viewed using a confocal laser scanning system [Nikon Eclipse E1000-M (Tokyo, Japan), Nikon Digital Eclipse C1] with a three-channel laser configuration: $488 \mathrm{~nm}$ argon laser, $543 \mathrm{~nm}$ helium-neon laser (both from Melles Griot Inc., Carlsbad, CA, USA), $638 \mathrm{~nm}$ diode laser (Coherent, Santa Clara, CA, USA). A $20 \times$ dry objective lens (numerical aperture 0.75) was used, the zoom factor was set to 2.0 in all scanning sessions.

In all wholemounts, each 15 ganglia or single neurons lying outside ganglia in interconnecting strands was selected randomly, in a meander-like fashion and three-line $z$-series were created (z-steps: $1.5 \mu \mathrm{m}$ ). All counts were carried out on these $z$-series, using the Nikon FreeViewer software (EZ-C1 3.30). We have tried to carefully discriminate neurons lying at the same $x-y$ but at different $z$-positions to avoid false positive recordings of neurons (e.g. one double-stained instead of two single-stained, overlapping neurons).

All figures are all-in-focus projections of $z$-series and were prepared using Adobe Photoshop CS (8.0.1) and CorelDraw 11.

Table 1 Antisera

\begin{tabular}{|c|c|c|c|}
\hline Antigen & Host & Dilution & Source \\
\hline \multicolumn{4}{|l|}{ Primary antisera } \\
\hline Choline acetyltransferase & Goat & $1: 40$ & AB144P; Millipore, Germany \\
\hline $\begin{array}{l}\text { Human neuronal protein } \\
\mathrm{Hu} \mathrm{C} / \mathrm{D}\end{array}$ & Mouse & $1: 50$ & A21271; Mobitec, Germany \\
\hline Nitric oxide synthase & Rabbit & $1: 400$ & $\begin{array}{l}\text { Dr. Mayer; University } \\
\text { of Graz, Austria }\end{array}$ \\
\hline \multicolumn{4}{|l|}{ Secondary antisera } \\
\hline ALEXA Fluor 647 & Donkey anti-goat & $1: 1,000$ & A-21447; Mobitec, Germany \\
\hline ALEXA Fluor 488 & Donkey anti-mouse & $1: 1,000$ & A-21202; Mobitec, Germany \\
\hline ALEXA Fluor 555 & Donkey anti-rabbit & $1: 1,500$ & A-31572; Mobitec, Germany \\
\hline
\end{tabular}




\section{Statistical evaluation}

For statistical analysis, we used the percentages of NOSpositive neurons among all HU-positive neurons counted in the 15 ganglia each. The similarity of the two control groups was confirmed by the independent two-sample $t$ test. Further analysis was performed against the two control groups combined. Differences between megacolonic patients, for all three segments separately (i.e. mean value of four oral, of four megacolonic and of four anal segments, respectively), and the (combined) control group were evaluated using the independent two-sample $t$ test (significance level $p<0.05$ ). Statistics were performed using SPSS Statistics 17 (Chicago, IL, USA).

\section{Results}

\section{Qualitative observations}

In Fig. 2, we have exemplarily depicted a myenteric ganglion of a non-megacolonic, non-chagasic patient. The four megacolonic samples, each composed of three wholemounts (from the oral, megacolonic and anal parts of the resected specimens, respectively), displayed quite different degrees of change as compared to the control samples. Therefore, we depicted representative ganglion triplets derived from three megacolonic patients (Figs. 3, 4, 5).

The myenteric plexus and ganglia of the seronegative patient (male, 69 years) resembled the corresponding structures of the control patients. At first glance, they showed no conspicuous pathological findings (Fig. 3).

The samples from the three seropositive patients displayed different changes of various severities. In Figs. 4 and 5, we tried to depict the spectrum of changes. Generally, the oral segments displayed no or only moderate changes, whereas the megacolonic and anal segments were more severely affected. In the oral wholemounts, it was not difficult to locate 15 ganglia containing neurons for quantitative assessment (see below). In contrast, in the megacolonic and anal preparations, we found numerous crossings of bulked fibre bundles where neurons were to be expected but, they appeared 'empty', without neurons. Mainly in the megacolonic and anal specimens, it was hard to locate 15 ganglia containing neurons. Partly, we were forced to prepare a second or even third wholemount per segment to complete our quantitative database.

In a number of specimens, we found ganglia with bulked fibre bundles and the spaces between these bundles appeared honeycomb-like (Figs. 4a, b, 5a-c). Mainly in the megacolonic and anal segments, ganglia displaying these honeycomb-like structures contained few or no neurons. Already visually (Figs. 4b, c, 5b, c), most of these neurons displayed NOS reactivity (NOS-neurons), only occasionally there were scattered ChAT-positive neurons (ChATneurons). The neuronal cell bodies in the megacolonic and anal wholemounts displayed a wider variety in size and shape than did those of the oral specimens (Figs. 4b, c, 5b, c). Some neurons (both NOS and ChAT) seemed markedly enlarged (hypertrophic, Fig. 4b), others appeared atrophic and/or strikingly deformed (Fig. 5b, c) and, in single cases, vacuolated. Mainly, the few leftover ChAT-neurons differed distinctly in their staining intensities (Fig. 4b).

\section{Quantitative evaluations: control samples}

In Fig. 6, we have illustrated percentages of four neuron populations gained from both control groups. We observed two larger populations, ChAT- and NOS-neurons, and two smaller populations, neurons co-immunoreactive for both ChAT and NOS (ChAT/NOS-neurons) and neurons negative for ChAT and NOS but positive for HU (HU-neurons).
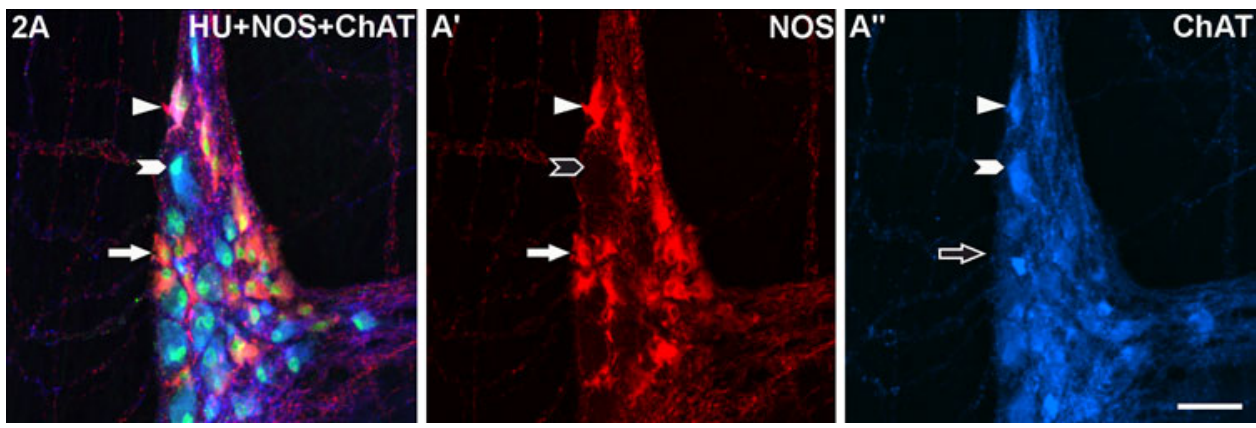

Fig. 2 A myenteric ganglion of a Brazilian non-chagasic, nonmegacolonic male patient aged 75 years stained for human neuronal protein $\mathrm{Hu} \mathrm{C} / \mathrm{D}(\mathrm{HU})$, neuronal nitric oxide synthase (NOS) and common choline acetyltransferase (ChAT). Exemplarily for all figures, the following colour combinations can be seen in the merged picture columns (left, respectively): NOS/HU-neurons appear orange (filled arrows in $\mathbf{a}, \mathbf{a}^{\prime}$; empty arrow in $\mathbf{a}^{\prime \prime}$ ), ChAT/HU-neurons turquoise (filled arrowheads in $\mathbf{a}, \mathbf{a}^{\prime \prime} ;$ empty arrowhead in $\mathbf{a}^{\prime}$ ), neurons co-immunoreactive for all three markers pink (triangles in $\mathbf{a}, \mathbf{a}^{\prime}, \mathbf{a}^{\prime \prime}$ ). A neuron reactive for HU but non-reactive for both NOS and ChAT is marked in Fig. 5a. Bar $50 \mu \mathrm{m}$ 
Fig. 3 Three myenteric ganglia of the megacolonic,

seronegative, male patient aged 69 years, stained for human neuronal protein $\mathrm{Hu}$ C/D (HU), neuronal nitric oxide synthase (NOS) and common choline acetyltransferase (ChAT). $\mathbf{a}$ is from the oral, $\mathbf{b}$ from the dilated (mega), $\mathbf{c}$ from the anal part of the resected colon segment. The structure of the ganglia appears largely normal and the quantitative relation of NOS- versus ChAT-reactive balanced. Exemplarily, ChAT/HU-neurons are marked with arrowheads, NOS/HUneurons with arrows, a ChAT/NOS/HU-neuron in c with triangles. Bar $50 \mu \mathrm{m}$ neurons is, at first glance,
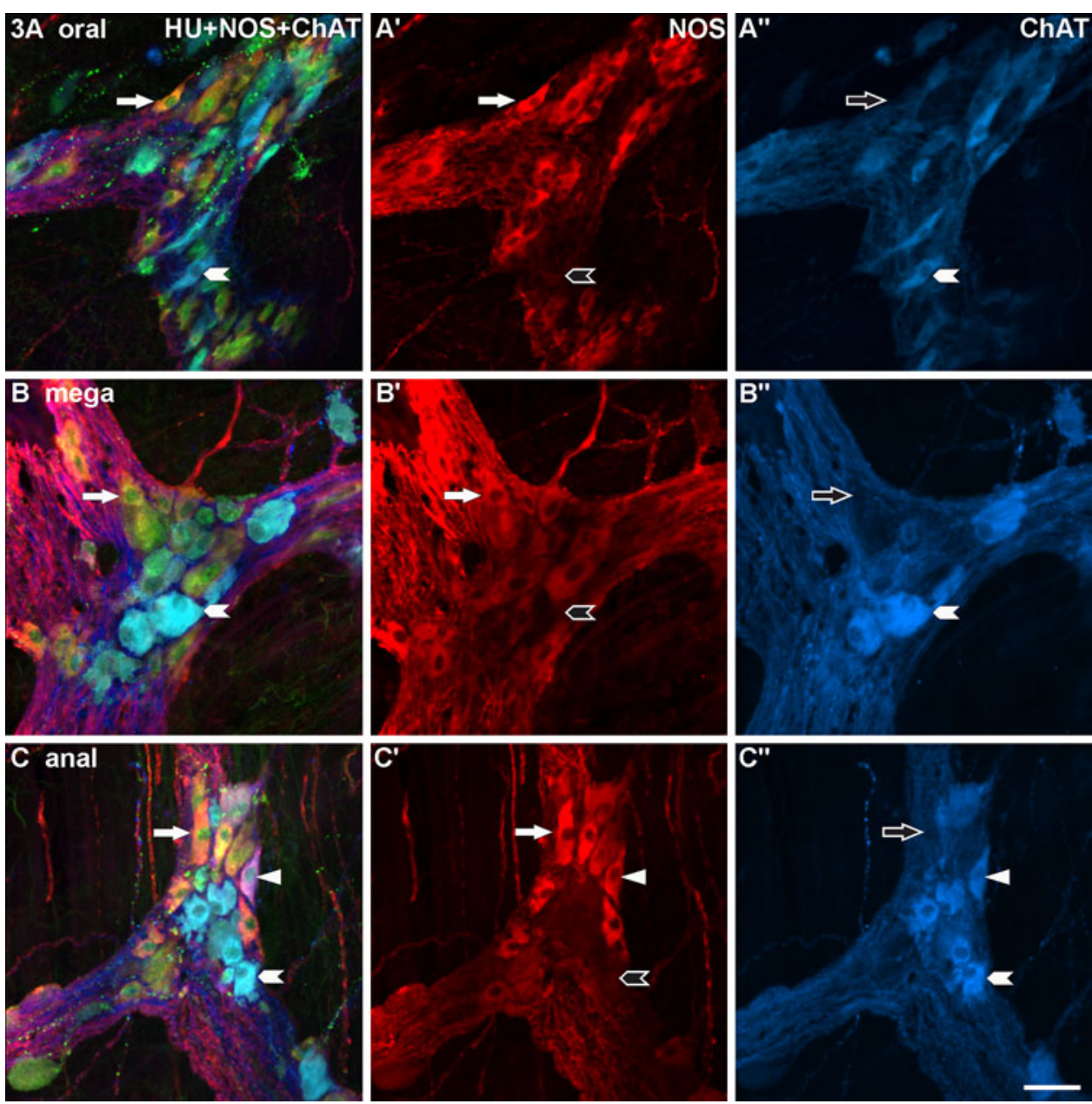

In the Brazilian control group, the percentages of NOS-neurons varied between 51 and $59 \%$ (mean 56\%), ChAT-neurons between 33 and 40\% (mean 34\%), ChAT/NOS-neurons between 2 and 4\% (mean 3\%) and HU-neurons between 3 and $9 \%$ (mean $7 \%$ ).

In the German control group, NOS-neurons varied between 50 and $59 \%$ (mean 54\%), ChAT-neurons between 33 and $47 \%$ (mean 40\%), ChAT/NOS-neurons between 1 and 6\% (mean $3 \%$ ) and HU-neurons between 2 and $5 \%$ (mean 3\%).

The difference between the mean percentages of NOSneurons was not significant (56 vs. $54 \%, p=0.639$ ).

The total number of neurons recorded per control patient varied between 230 per 15 ganglia/view fields (mean 15.3) and 595 per 15 ganglia/view fields (mean 39.7). The total number of neurons of all 12 control specimens amounted to 5,296 neurons per 180 ganglia/view fields (mean 29.4).

Quantitative evaluations: megacolonic samples

In Fig. 7, we have illustrated percentages of the four neuron populations described above but gained from the megacolonic patient group. Right from visual impression (see above), there were much fewer neurons than in control samples, mainly in the megacolonic and anal segments. This is indicated, though not thoroughly evident, by the lower numbers per 15 ganglia marked below the columns, respectively.

The percentages of NOS-neurons were significantly, in part drastically, increased. Again, this was more striking in the megacolonic and, even more, in the anal segments. In the oral segments, NOS-neurons amounted from 57 to $67 \%$ (oral mean $61 \%$ vs. control mean $55 \%, p=0.003$ ), in the megacolonic segments from 64 to $81 \%$ (mean 72 vs. $55 \%, p<0.001)$ and in the anal segments from 61 to $86 \%$ (mean 78 vs. $55 \%, p<0.001$ ). Also, the percentages of ChAT/NOS-neurons were partly increased, up onto $18 \%$ in the megacolonic segment of the male patient aged 59 years. In contrast, the percentages of ChAT-neurons were dramatically decreased, down to $3 \%$ in the anal segments of the two female patients.

As to the total neuron numbers recorded per patient, these were within the range of the control values in the seronegative patient and within all oral segments of the three seropositive patients. They were lower than the lowest control value (230 per 15 ganglia; mean 15.3 ) in all megacolonic and anal segments of the three seropositive 
Fig. 4 Three myenteric ganglia gained from wholemounts of the megacolonic, seropositive, female patient aged 69 years, stained for human neuronal protein $\mathrm{Hu} \mathrm{C} / \mathrm{D}(\mathrm{HU})$, neuronal nitric oxide synthase (NOS) and common choline acetyltransferase (ChAT). $\mathbf{a}$ is from the oral, $\mathbf{b}$ from the dilated (mega), $\mathbf{c}$ from the anal part of the resected specimen. The ganglion in a appears, though some honeycomb-like structures (asterisks), still normal, the ganglion in $\mathbf{b}$ is strikingly bulked (asterisks). In a, there is a quite balanced quantitative relation between NOS- and ChAT-neurons, in $\mathbf{b}$ and $\mathbf{c}$, the ganglia contain predominantly NOS-neurons (exemplarily: arrows). Mainly in $\mathbf{b}$, the NOS-neurons differ considerably in size (compare the two arrowed neurons). Two marked ChAT-neurons in $\mathbf{b}^{\prime \prime}$ differ markedly in their staining intensities (compare the arrowheaded with the triangled neuron, the latter is additionally co-reactive for NOS and HU: triangles). Bar $50 \mu \mathrm{m}$
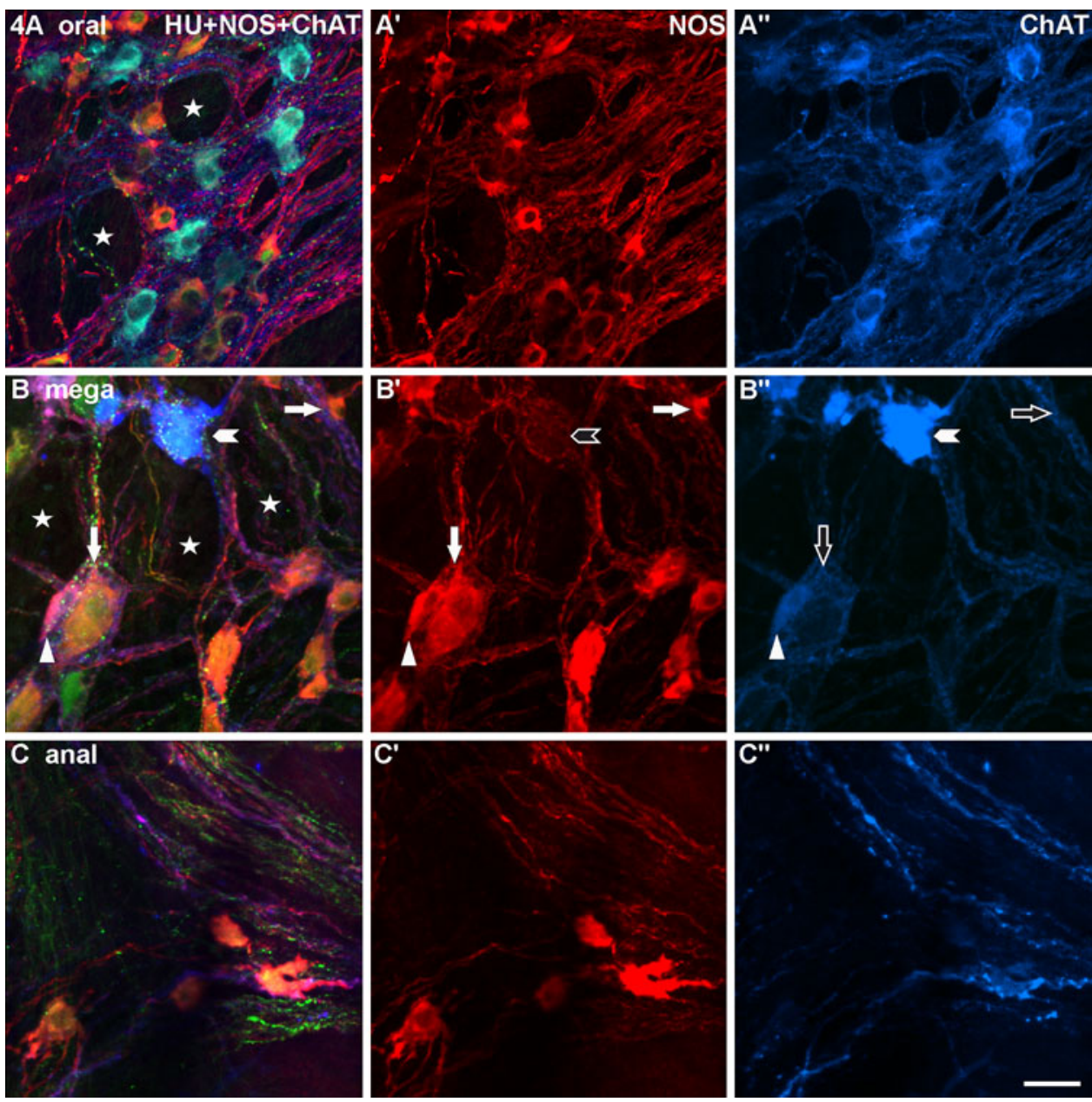

patients. Here, the lowest number was 61 neurons per 15 ganglia/view fields (mean 4.1), the highest number was 185 neurons per 15 ganglia/view fields (mean 12.3).

\section{Discussion}

This study demonstrated a relative increase of nitrergic (NOS) myenteric neurons among all four megacolonic samples. Surprisingly, this increase was most pronounced in the non-dilated anal segment, considerably pronounced in the megacolonic segment and still detectable in the nondilated oral segment. Although the leading clinical and pathological feature of all four megacolonic samples was their chronic dilation indicating the severely disturbed gut motility (aperistalsis), the chagasic background could be verified only in three of four patients.

\section{Seropositive versus seronegative megacolon}

The impressive neuronal, ChAT/NOS-imbalance found in this study is confined to the seropositive group and does affect the seronegative patient with megacolon to a lesser extent. Clinical and macroscopic features in the seronegative megacolon sample were more compatible with chagasic rather than control samples. The most likely explanation for the seronegative megacolon may be seroconversion (Fabbro et al. 2007; Escribà et al. 2009). Other considerations may include analytical errors (i.e. very low serologic levels, poor sample quality) or the exceedingly rare presentation of a megacolon without chagasic background in an adult. However, based on our neurochemical characterization as well as the endemic nature of Chagas' disease in this particular region in Brazil, we interpret our findings in the seronegative patient as compatible with seroconversion in this highly variable disease.

\section{Morphologic changes in megacolonic myenteric plexus and ganglia}

Apart from species differences, morphology of enteric neurons, ganglia and plexus depends on the method used for representation (Brehmer 2006). Thus, comparison of enteric neuronal structures between supposed normal and 
Fig. 5 Three myenteric ganglia of the megacolonic,

seropositive, male patient aged 59 years, stained for human neuronal protein $\mathrm{Hu}$ C/D (HU), neuronal nitric oxide synthase (NOS) and common choline acetyltransferase (ChAT). $\mathbf{a}$ is from the oral, $\mathbf{b}$ from the dilated (mega), $\mathbf{c}$ from the anal part of the resected specimen. In all three ganglia $(\mathbf{a}-\mathbf{c})$, a

honeycomb-like structure is obvious (asterisks). In a, the quantitative relation between NOS- and ChAT-neurons is largely balanced, in $\mathbf{b}$, there are only NOS-neurons

(exemplarily: arrows), in c,

NOS- outnumber ChAT-

neurons strikingly (exemplarily: arrows and arrowheads, respectively). Mainly in $\mathbf{b}$, the neurons are distinctly deformed. In $\mathbf{a}-\mathbf{a}^{\prime \prime}$, a neuron

immunoreactive for $\mathrm{HU}$ (green; filled triangle) but neither for

NOS nor for ChAT (empty triangles) is marked. Bar $50 \mu \mathrm{m}$

Fig. 6 Percentages of left colonic, myenteric neurons as estimated in wholemounts which were derived from Brazilian (left six columns) and German (right six columns) control patients and which were stained for human neuronal protein $\mathrm{Hu}$ C/D (HU), neuronal nitric oxide synthase (NOS) and common choline

acetyltransferase (ChAT). The mean values were opposed in the middle three columns, respectively ( $B M$ Brazilian mean, $G M$ German mean, $T M$ total mean). Numbers within the columns indicate, from below, percentages of NOS-, ChAT/ NOS-, ChAT- and HU-neurons. Numbers below the columns indicate the counts of neurons recorded in 15 ganglia, respectively
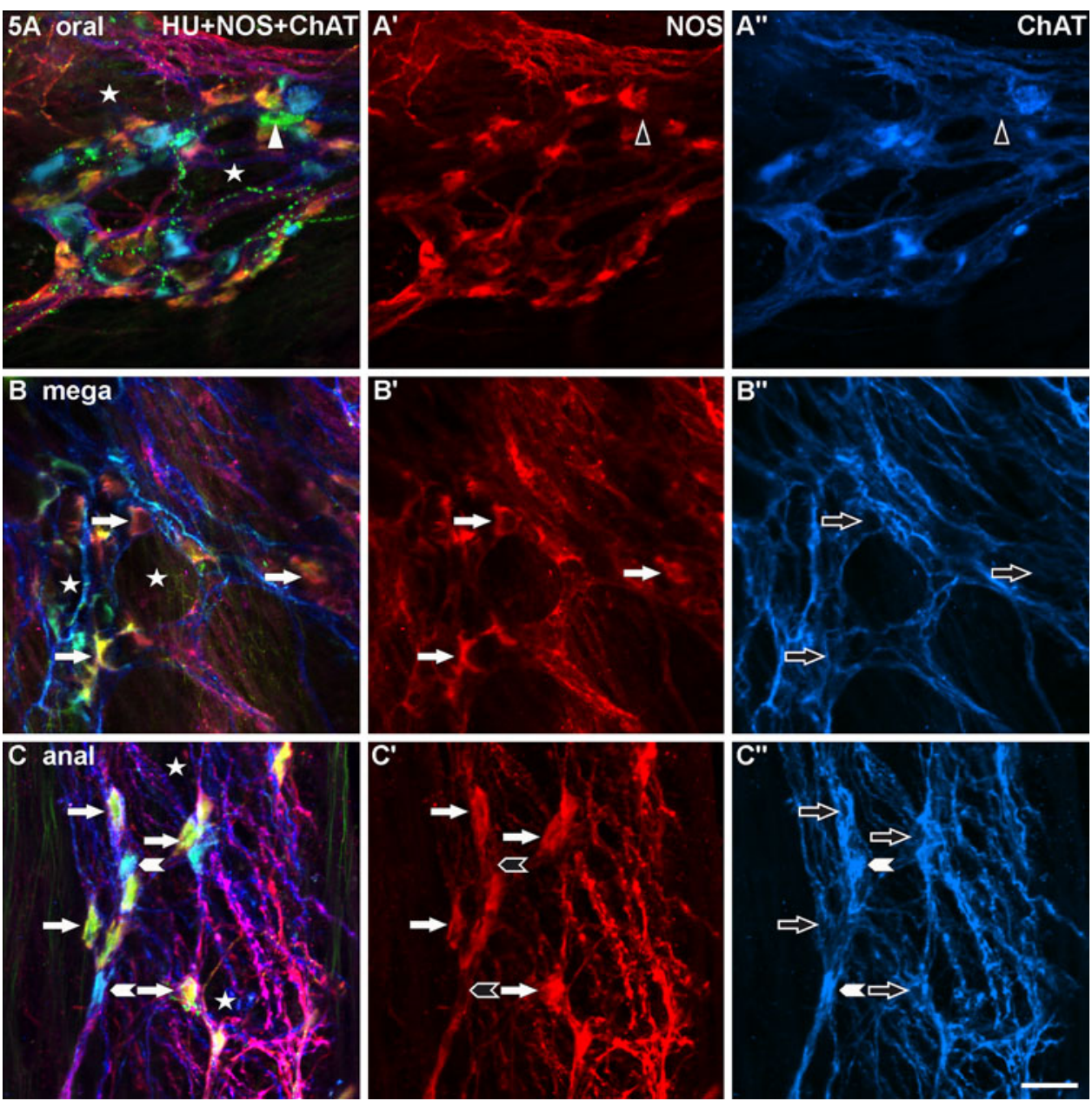

\section{aU only $\quad$ ChAT $\quad$ ChAT/NOS NOS}

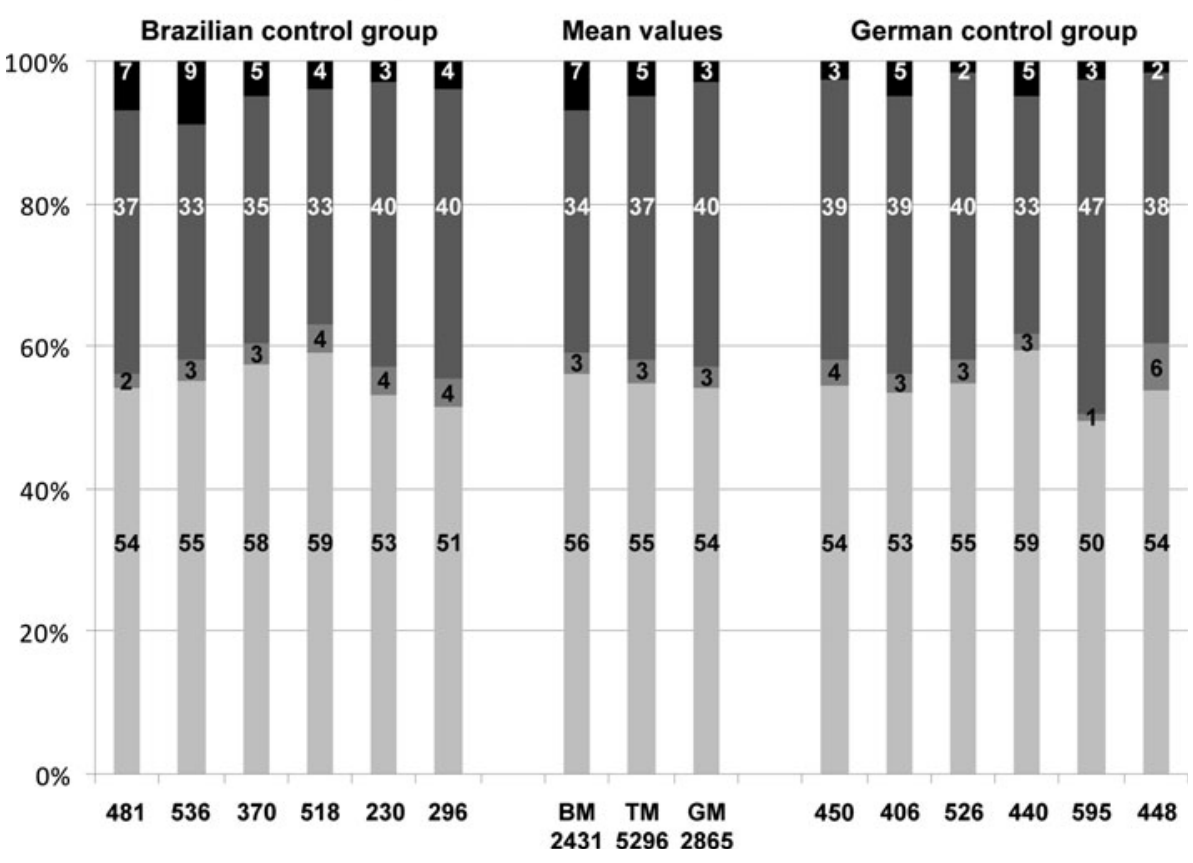




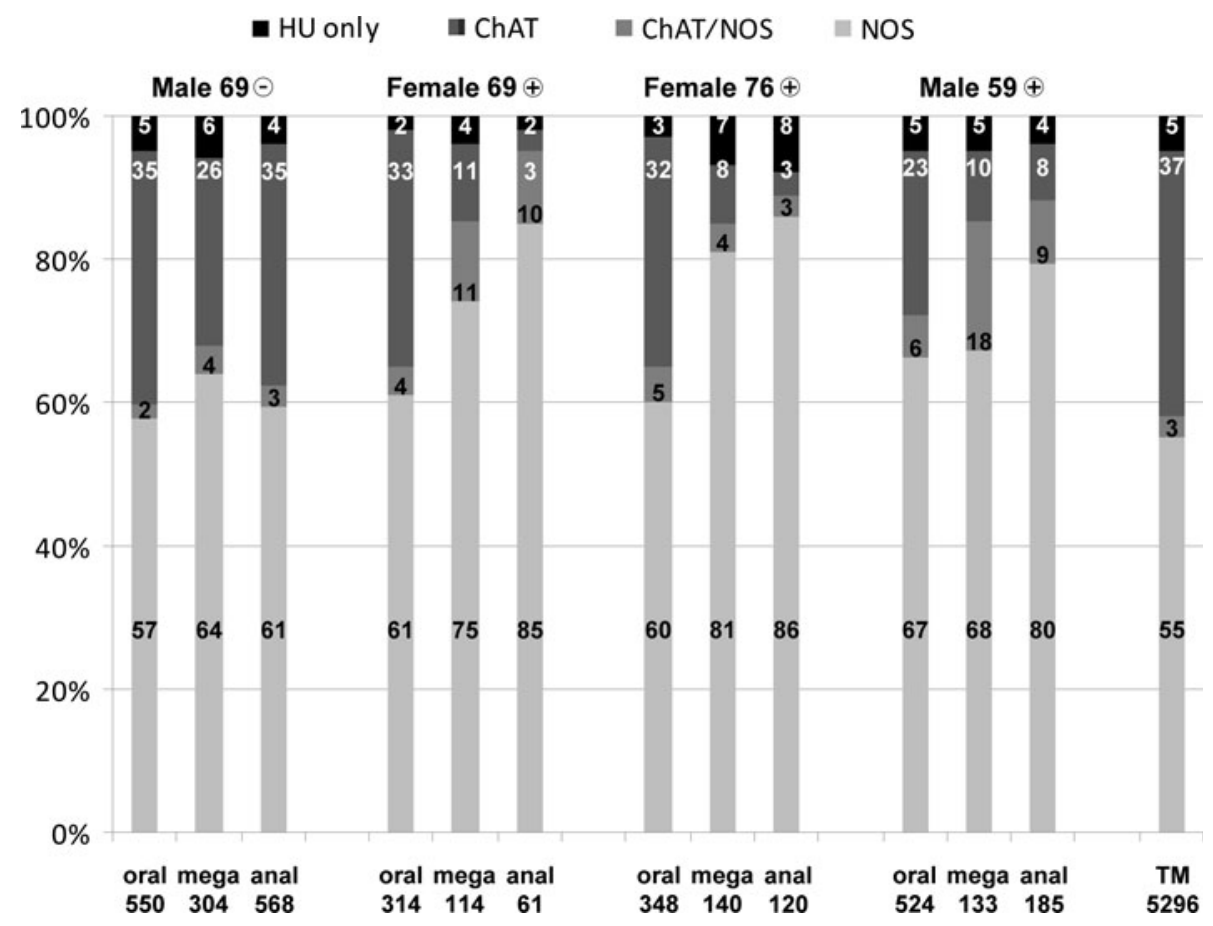

Fig. 7 Percentages of left colonic, myenteric neurons as estimated in wholemounts which were derived from four megacolonic patients and stained for human neuronal protein $\mathrm{Hu} \mathrm{C} / \mathrm{D}(\mathrm{HU})$, neuronal nitric oxide synthase (NOS) and common choline acetyltransferase (ChAT). The four triple columns represent the percentages of the oral, megacolonic (mega) and anal parts of the four surgically removed, megacolonic segments, respectively. The data of the patients were

megacolonic samples is best done by opposing results of studies based on the same staining combination as we used here. Comparing the myenteric structures derived from our control groups with those of Murphy et al. (2007) and Beck et al. (2009), we found that the myenteric plexus of the megacolonic but seronegative patient (male 69) including its ganglia and neurons displayed largely normal morphology. The other three samples revealed morphological changes we interpret as prototypic signs of neurodegeneration which were most distinct in the anal (non-dilated) and the megacolonic regions. Instead of ganglia containing numerous neurons, we found a network of bulky fibre bundles, honeycomb-like plexus structures and 'empty' ganglia without nerve cells. Comparable structures have earlier been demonstrated, by applying various methods, in colonic specimens derived from quite different diseases, both megacolonic and non-megacolonic, and from aged colon (De Biscop 1949; Smith 1972; Schuffler et al. 1978, 1985; Schuffler and Jonak 1982; Krishnamurthy et al. 1985; Hanani et al. 2004).

The normal morphological heterogeneity of enteric neuron types is considerably based on shapes of processes (Dogiel 1899; Stach 1989; Furness 2006; Brehmer 2006) and is far from being established, thus unconsidered in indicated above the triple columns each (gender, age, seronegative or seropositive). The most right column represents the total control percentages of 12 control patients (TM, total mean of Fig. 5). Numbers within the columns indicate, from below, percentages of NOS-, ChAT/NOS-, ChAT- and HU-neurons. Numbers below the columns indicate the counts of neurons recorded in 15 ganglia, respectively

current routine histopathology. Given that assessment of neuronal processes is limited by the staining pattern used in this study, 'neuronal morphology' refers only to sizes and shapes of the nerve cell bodies. The observed features in our megacolonic samples (atrophy, swelling, vacuolated or fenestrated cytoplasm) are consistent with diagnostic criteria of degenerating central neurons (Seilhean et al. 2004). The overall variability of perikaryal sizes and shapes in our chagasic samples was more pronounced when compared directly to our control groups or to existing reports (Murphy et al. 2007; Beck et al. 2009). Also in neurohistopathologic diagnostics of intestinal diseases, the term 'anisomorphism' (Meier-Ruge and Bruder 2005) refers to changes of neuronal perikarya.

\section{Partial, selective survival of nitrergic neurons}

Chagasic megacolon has been traced back to extensive neuron loss in the affected gut segment (Köberle 1968; Fernandez et al. 1992; Meneghelli 2004; Iantorno et al. 2007). This general neuron loss was apparent mainly in the megacolonic and anal regions of our samples and is indicated, though not thoroughly evident, by the lower numbers of neurons per 15 ganglia/view fields as represented in 
Fig. 7 (below the columns). We emphasize that our quantifying approach was aimed at characterizing relative, not absolute changes in neuron numbers. These latter have been described earlier (see above).

In our samples, nitrergic neurons, as compared with cholinergic neurons, seemed to be more resistant against the pathological factors causing neuron loss. Relative increase of nitrergic, enteric neurons as a consequence of selective loss of cholinergic neurons has also been observed with ageing in both animal experiments and human studies (Santer 1994; Phillips et al. 2003; Bernard et al. 2009). Similarly, nitrergic nerve elements were spared from reduction in mice infected with $T$. cruzi ( $\mathrm{Ny}$ et al. 1999), in rat experimental colitis (Lin et al. 2005) and were found in excess in idiopathic chronic constipation (Cortesini et al. 1995). Accordingly, Yoshida et al. (1988) found a loss of substance P- and enkephalin-immunoreactive, supposed cholinergic, nerve fibres in a megacolonic segment. Machado et al. (1987) recorded, though transiently, reduced enzyme activity of ChAT in colonic samples of experimentally $T$. cruzi-infected rats. A possible explanation for the more pronounced responsiveness of cholinergic neurons against intracellular invasion with the parasite $T$. cruzi, the chagasic pathogen, may be a change in the cholinergic gene expression in enteric neurons (Akpan et al. 2008).

There are contradictory studies reporting on a decrease of nitrergic neurons in chagasic, megacolonic specimens (Ribeiro et al. 1998; da Silveira et al. 2007). However, Ribeiro et al. (1998) stained nitrergic neurons by a histochemical reaction, without counterstaining of any other population. Most likely, there were much less nitrergic elements in the megacolonic versus control specimens, but this absolute decrease is also a relative increase as shown here. In the other study (da Silveira et al. 2007), sections instead of wholemounts and a smaller number of neurons were investigated. We suggest that the much greater number of neurons recorded here enables a more realistic view on the degeneration of the myenteric plexus.

Among all enteric neuron types which fulfil either sensory and/or interneuronal and/or effectory roles, most are either nitrergic or cholinergic. This is best known from the guinea pig small intestine (Furness 2006). Whereas nitrergic neurons are supposed to function either as descending interneurons or as inhibitory motor neurons, cholinergic neurons display a wider variety of subtypes. Among these, there are excitatory motor neurons. It is tempting to explain the development of megacolon in chagasic patients with the development of a quantitative imbalance in motor innervation between cholinergic/ excitatory and nitrergic/inhibitory motor neurons in favour of the latter. Since nitrergic neurons exert an inhibitory influence to the intestinal muscle, their preponderance would lead to more relaxation.
To our mind, it is only a seeming contradiction that the anal parts of the resected segments displayed a distinct neuronal overbalance of nitrergic neurons but no dilation. The absolute decrease of nitrergic neuronal input to the muscle and the questionable ability of the remaining immunohistochemically detectable NOS-neurons to produce adequate amounts of nitric oxide concerns both the megacolonic and anal regions. One explanation may be that the anal part of the surgically removed segment is immediately oral to the more anal colonic/rectal segment that was left in the patient. Although not known, this may display a balanced cholinergic-nitrergic motor innervation. Some of the cholinergic neuron types have ascending axonal projections, best known from the guinea pig (Furness 2006). The longest oral projection distances demonstrated in this small laboratory animal are $14 \mathrm{~mm}$ (Brookes et al. 1997), in human almost $4 \mathrm{~cm}$ long oral projections of supposed interneurons were shown so far (Wattchow et al. 1995). Such ascending axons may have provided the non-dilated anal segment with cholinergic and tachykinergic, excitatory input (Porter et al. 1997, 2002; Wattchow et al. 1997). Despite striking cholinergic cell body loss in the investigated, anal region, the proposed ascending, excitatory input from more anally located, preserved segments may have resulted in a more balanced motor pattern and in no chronic dilation in the anal region of the surgically removed segment. In contrast, the megacolonic region of the removed segment may be too remote from adequate ascending cholinergic input derived from more anal, supposedly not affected myenteric ganglia. Since the absolute nerve cell loss may have been most pronounced in the anal segments, another explanation may be that here even the nitrergic input to the muscle may be too low to effect dilation (resembling the situation in Hirschsprung's disease).

In addition, with the dramatic loss of cholinergic neurons also afferent and several types of interneurons disappear from the afflicted segment. Considering this loss of most components of enteric circuitry, regular motor patterns of the colon (e.g. peristalsis) are no longer conceivable. Results of studies on chagasic heart failures suggest damages of different tissues (conduction tissue, myocardium, microvasculature) which contribute to the clinical symptoms of cardiomyopathies (Tanowitz et al. 1992).

Megacolon in seropositive versus seronegative patients

Although the imbalance between the two efferent limbs of motor innervation, cholinergic versus nitrergic, was least pronounced in the seronegative patient, the megacolon as macroscopic feature of severely disturbed motility indicated surgical removal of the affected segment. During the decades lasting, chronic phase of Chagas' disease, megacolon becomes clinically manifest by a slowly progressive 
constipation (de Oliveira et al. 1998). Pronounced neuron loss is assumed to start in the acute phase by direct, pathogenic action of the parasite, whereas it continues during the chronic phase by the immunologic defense of the organism (Köberle 1968; Hudson and Hindmarsh 1985; Dutra et al. 2009), although the parasite mostly does not disappear completely from the afflicted host (Clayton 2010). It was suggested that loss of about half of the colonic enteric neurons is required to transform the previously occurring 'functional' motility dysbalance into a 'morphological' megacolon (Köberle 1968). The absolute amount of neuron loss has not been investigated here but, based on subjective visual evaluation of our myenteric plexus specimens, we suggest that it was more moderate in the seronegative as compared to the three seropositive patients. The formation of megacolon may depend on a certain degree of imbalance between cholinergic and nitrergic motor neurons and neuron death may continue thereafter.

In conclusion, the extensive neuron loss in chagasic megacolon concerns cholinergic neurons to a higher degree than nitrergic neurons, although the absolute number of the latter may also have been decreased. The resulting predominance of nitrergic, inhibitory nervous elements may contribute to the development of megacolon during the chronic phase of Chagas' disease. While ongoing investigations will have to delineate changes in other components of the intestinal motor system, e.g. submucosal neurons, glial cells, interstitial cells of Cajal and the effector tissue smooth muscle, our findings emphasize the altered neurochemical profile as part of the disease spectrum underlying disturbed gut motility in chagasic megacolon.

Acknowledgments The excellent technical assistance of Karin Löschner, Stefanie Link, Anita Hecht, Andrea Hilpert, Hedwig Symowski and Inge Zimmermann (all Erlangen, Germany) is gratefully acknowledged. The authors also appreciate the thoughtful discussions with Jochen K. Lennerz (Department of Pathology, Massachusetts General Hospital/Harvard Medical School, Boston, MA, USA). This work was supported by funds from CNPq (Conselho Nacional de Desenvolvimento Científico e Tecnológico), FIOCRUZ (Fundação Oswaldo Cruz), PAPES V (Programa de Apoio a Pesquisa Estratégica em Saúde) and Deutsche Forschungsgemeinschaft (BR 1815/4-1).

Open Access This article is distributed under the terms of the Creative Commons Attribution Noncommercial License which permits any noncommercial use, distribution, and reproduction in any medium, provided the original author(s) and source are credited.

\section{References}

Akpan N, Caradonna K, Chuenkova MV, PereiraPerrin M (2008) Chagas' disease parasite derived neurotrophic factor activates cholinergic gene expression in neuronal PC12 cells. Brain Res 1217:195-202
Beck M, Schlabrakowski A, Schrödl F, Neuhuber W, Brehmer A (2009) ChAT and NOS in human myenteric neurons: coexistence and co-absence. Cell Tissue Res 338:37-51

Bernard CE, Gibbons SJ, Gomez-Pinilla PJ, Lurken MS, Schmalz PF, Roeder JL, Linden D, Cima RR, Dozois EJ, Larson DW, Camilleri M, Zinsmeister AR, Pozo MJ, Hicks GA, Farrugia G (2009) Effect of age on the enteric nervous system of the human colon. Neurogastroenterol Motil 21:746-754

Brehmer A (2006) Structure of enteric neurons. Adv Anat Embryol Cell Biol 186:1-94

Brehmer A, Blaser B, Seitz G, Schrödl F, Neuhuber W (2004) Pattern of lipofuscin pigmentation in nitrergic and non-nitrergic, neurofilament immunoreactive myenteric neuron types of human small intestine. Histochem Cell Biol 121:13-20

Brookes SJ, Meedeniya AC, Jobling P, Costa M (1997) Orally projecting interneurones in the guinea-pig small intestine. J Physiol 505(Pt 2):473-491

Clayton J (2010) Chagas disease 101. Nature 465:S4-S5

Cortesini C, Cianchi F, Infantino A, Lise M (1995) Nitric oxide synthase and VIP distribution in enteric nervous system in idiopathic chronic constipation. Dig Dis Sci 40:2450-2455

Coura JR, Vinas PA (2010) Chagas disease: a new worldwide challenge. Nature 465:S6-S7

da Silveira AB, D'Avila Reis D, de Oliveira EC, Neto SG, Luquetti AO, Poole D, Correa-Oliveira R, Furness JB (2007) Neurochemical coding of the enteric nervous system in chagasic patients with megacolon. Dig Dis Sci 52:2877-2883

De Biscop G (1949) Über pathologische Veränderungen am Auerbachschen Plexus bei Megacolon. Z Zellforsch Mikrosk Anat 34:141-159

de Oliveira RB, Troncon LE, Dantas RO, Menghelli UG (1998) Gastrointestinal manifestations of Chagas' disease. Am J Gastroenterol 93:884-889

Di Nardo G, Blandizzi C, Volta U, Colucci R, Stanghellini V, Barbara G, Del Tacca M, Tonini M, Corinaldesi R, De Giorgio R (2008) Review article: molecular, pathological and therapeutic features of human enteric neuropathies. Aliment Pharmacol Ther 28:25-42

Dogiel AS (1899) Ueber den Bau der Ganglien in den Geflechten des Darmes und der Gallenblase des Menschen und der Säugethiere. Arch Anat Physiol Anat Abt (Leipzig):130-158

Dutra WO, Menezes CA, Villani FN, da Costa GC, da Silveira AB, Reis D, Gollob KJ (2009) Cellular and genetic mechanisms involved in the generation of protective and pathogenic immune responses in human Chagas disease. Mem Inst Oswaldo Cruz 104(Suppl 1):208-218

Escribà JM, Ponce E, Romero Ade D, Vinas PA, Marchiol A, Bassets G, Palma PP, Lima MA, Zuniga C, Ponce C (2009) Treatment and seroconversion in a cohort of children suffering from recent chronic Chagas infection in Yoro, Honduras. Mem Inst Oswaldo Cruz 104:986-991

Fabbro DL, Streiger ML, Arias ED, Bizai ML, del Barco M, Amicone NA (2007) Trypanocide treatment among adults with chronic Chagas disease living in Santa Fe city (Argentina), over a mean follow-up of 21 years: parasitological, serological and clinical evolution. Rev Soc Bras Med Trop 40:1-10

Fernandez A, Hontebeyrie M, Said G (1992) Autonomic neuropathy and immunological abnormalities in Chagas' disease. Clin Auton Res 2:409-412

Furness JB (2006) The enteric nervous system. Blackwell, Oxford

Ganns D, Schrödl F, Neuhuber W, Brehmer A (2006) Investigation of general and cytoskeletal markers to estimate numbers and proportions of neurons in the human intestine. Histol Histopathol 21:41-51

Grider JR (1989) Identification of neurotransmitters regulating intestinal peristaltic reflex in humans. Gastroenterology 97:1414-1419 
Hanani M, Fellig Y, Udassin R, Freund HR (2004) Age-related changes in the morphology of the myenteric plexus of the human colon. Auton Neurosci 113:71-78

Heanue TA, Pachnis V (2007) Enteric nervous system development and Hirschsprung's disease: advances in genetic and stem cell studies. Nat Rev Neurosci 8:466-479

Howard ER (1972) Hirschsprung's disease: a review of the morphology and physiology. Postgrad Med J 48:471-477

Hudson L, Hindmarsh PJ (1985) The relationship between autoimmunity and Chagas' disease: causal or coincidental? Curr Top Microbiol Immunol 117:167-177

Iantorno G, Bassotti G, Kogan Z, Lumi CM, Cabanne AM, Fisogni S, Varrica LM, Bilder CR, Munoz JP, Liserre B, Morelli A, Villanacci V (2007) The enteric nervous system in chagasic and idiopathic megacolon. Am J Surg Pathol 31:460-468

Köberle F (1968) Chagas' disease and Chagas' syndromes: the pathology of American trypanosomiasis. Adv Parasitol 6:63-116

Krishnamurthy S, Schuffler MD, Rohrmann CA, Pope CE (1985) Severe idiopathic constipation is associated with a distinctive abnormality of the colonic myenteric plexus. Gastroenterology $88: 26-34$

Lin A, Lourenssen S, Stanzel RD, Blennerhassett MG (2005) Selective loss of NGF-sensitive neurons following experimental colitis. Exp Neurol 191:337-343

Machado CR, Gomez MV, Machado AB (1987) Changes in choline acetyltransferase activity of rat tissues during Chagas' disease. Braz J Med Biol Res 20:697-702

Meier-Ruge WA, Bruder E (2005) Pathology of chronic constipation in pediatric and adult coloproctology. Pathobiology 72:1-102

Meneghelli UG (2004) Chagasic enteropathy. Rev Soc Bras Med Trop 37:252-260

Murphy EM, Defontgalland D, Costa M, Brookes SJ, Wattchow DA (2007) Quantification of subclasses of human colonic myenteric neurons by immunoreactivity to $\mathrm{Hu}$, choline acetyltransferase and nitric oxide synthase. Neurogastroenterol Motil 19:126-134

Ny L, Persson K, Larsson B, Chan J, Weiss LM, Wittner M, Huang H, Tanowitz HB (1999) Localization and activity of nitric oxide synthases in the gastrointestinal tract of Trypanosoma cruziinfected mice. J Neuroimmunol 99:27-35

Phillips RJ, Kieffer EJ, Powley TL (2003) Aging of the myenteric plexus: neuronal loss is specific to cholinergic neurons. Auton Neurosci 106:69-83

Phillips RJ, Hargrave SL, Rhodes BS, Zopf DA, Powley TL (2004) Quantification of neurons in the myenteric plexus: an evaluation of putative pan-neuronal markers. J Neurosci Methods 133:99-107

Porter AJ, Wattchow DA, Brookes SJ, Costa M (1997) The neurochemical coding and projections of circular muscle motor neurons in the human colon. Gastroenterology 113:1916-1923

Porter AJ, Wattchow DA, Brookes SJ, Costa M (2002) Cholinergic and nitrergic interneurones in the myenteric plexus of the human colon. Gut 51:70-75
Ribeiro U, Safatle-Ribeiro AV, Habr-Gama A, Gama-Rodrigues JJ, Sohn J, Reynolds JC (1998) Effect of Chagas' disease on nitric oxide-containing neurons in severely affected and unaffected intestine. Dis Colon Rectum 41:1411-1417

Santer RM (1994) Survival of the population of NADPH-diaphorase stained myenteric neurons in the small intestine of aged rats. J Auton Nerv Syst 49:115-121

Schnell SA, Staines WA, Wessendorf MW (1999) Reduction of lipofuscin-like autofluorescence in fluorescently labeled tissue. J Histochem Cytochem 47:719-730

Schuffler MD, Jonak Z (1982) Chronic idiopathic intestinal pseudoobstruction caused by a degenerative disorder of the myenteric plexus: the use of Smith's method to define the neuropathology. Gastroenterology 82:476-486

Schuffler MD, Bird TD, Sumi SM, Cook A (1978) A familial neuronal disease presenting as intestinal pseudoobstruction. Gastroenterology 75:889-898

Schuffler MD, Leon SH, Krishnamurthy S (1985) Intestinal pseudoobstruction caused by a new form of visceral neuropathy: palliation by radical small bowel resection. Gastroenterology 89:1152-1156

Seilhean D, De Girolami U, Gray F (2004) Basic pathology of the central nervous system. In: Gray F, De Girolami U, Poirier J (eds) Manual of basic neuropathology. Butterworth, Heinemann, PA, pp 1-20

Smith B (1972) The neuropathology of the alimentary tract. Edward Arnold, London

Stach W (1989) A revised morphological classification of neurons in the enteric nervous system. In: Singer MV, Goebell H (eds) Nerves and the gastrointestinal tract. Kluwer, Lancaster, pp 29-45

Tanowitz HB, Kirchhoff LV, Simon D, Morris SA, Weiss LM, Wittner M (1992) Chagas' disease. Clin Microbiol Rev 5:400-419

Teixeira AR, Nitz N, Guimaro MC, Gomes C, Santos-Buch CA (2006) Chagas disease. Postgrad Med J 82:788-798

Thapar N (2009) New frontiers in the treatment of Hirschsprung disease. J Pediatr Gastroenterol Nutr 48(Suppl 2):S92-S94

Wattchow DA, Brookes SJ, Costa M (1995) The morphology and projections of retrogradely labeled myenteric neurons in the human intestine. Gastroenterology 109:866-875

Wattchow DA, Porter AJ, Brookes SJ, Costa M (1997) The polarity of neurochemically defined myenteric neurons in the human colon. Gastroenterology 113:497-506

Yoshida MM, Krishnamurthy S, Wattchow DA, Furness JB, Schuffler MD (1988) Megacolon in myotonic dystrophy caused by a degenerative neuropathy of the myenteric plexus. Gastroenterology 95:820-827 